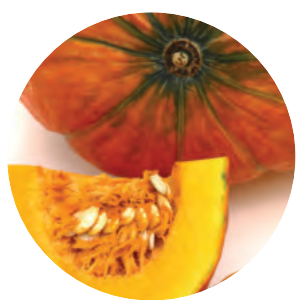

\title{
CONVEYOR OF VARIETIES OF PUMPKIN OF FEDERAL RESEARCH VEGETABLE CENTER (VNIISSOK) SELECTION
}

Химич Г.А. - С.Н.С. лаб. селекции и семеноводства тыквенных культур Коротцева И.Б. - зав. лаб. селекции и семеноводства тыквенных культур, кандидат с.-Х. наук

ФГБНУ «Федеральный научный центр овощеводства 143080, Россия, Московская область, Одинцовский район, пос. ВНИИССОК, ул, Селекционная, д. 14 E-mail: korottseva@mail.ru

Во ВНИИ селекции и семеноводства овощных культур (ФГБНУ ФНЦО) создан ряд скороспелых, холодостойких, урожайных, устойчивых к ряду заболеваний сортов и гибридов тыквы столовой, характеризующихся высокими вкусовыми и технологическими качествами плодов. Большинство сортов тыквы нуждается в дозаривании плодов для улучшения их вкусовых качеств. Позднеспелые сорта при длительном хранении плодов, до конца ноября - начала декабря, накапливают до 10\% суммы сахаров. Сроки дозаривания и хранения плодов тыквы без потери качественных и вкусовых показателей индивидуальны для каждого сорта и могут сильно различаться между собой. Выведены сорта тыквы столовой как практически не нуждающиеся, так и нуждающиеся в дозаривании - от двух недель до двух месяцев. В значительной степени различаются все сорта и по срокам хранения плодов. Используя эти особенности сортов, даже в условиях Московской области можно создать непрерывный конвейер потребления плодов тыквы столовой. Даны рекомендации по срокам дозаривания и использования плодов разных сортов тыквы селекции ВНИИССОК (НЫне ФГБНУ ФНЦО).

Ключевые слова: тыква, сорт, гибрид, дозаривание, хранение, биохимический состав, технологические качества.

Для цитирования: Химич Г.А., Коротцева И.Б. КОНВЕЙЕР СОРТОВ ТЫКВЫ СТОЛОВОЙ СЕЛЕКЦИИ ВНИИССОК. ОВОщИ РОССИИ. 2018;(1):63-65. DOI:10.18619/2072-9146-2018-1-63-65

\author{
Khimich G.A. \\ Korotseva I.B.
}

\section{FSBSI Federal Scientific Vegetable Center}

Selectionaya St. 14, VNIISSOK, Odintsovo region, Moscow oblast, 143072, Russia E-mail: korottseva@mail.ru

Several early ripening pumpkin varieties adn hybrids with high yield and resistance to cold and diseases and high organoleptic properties were developed in Federal Scientific Vegetable Cencer. They are early, cold-resistant, yielding and resistant to a diseases and they have high taste and technological qualities of fruits. Most varieties of pumpkin need to fruit ripening to improve their taste. Lateripening varieties with long-term storage of fruits, until the end of November - early December, accumulate up to $10 \%$ of the amount of sugars. The timing of pumpering and storage of pumpkin fruits without loss of quality and taste indicators are individual for each variety and can vary greatly between each other. Gourds of a pumpkin of a dining room are shown as practically not requiring, and requiring in fruit ripening - from two weeks to two months. To a large extent, all varieties differ in terms of the shelf life of the fruit. Using these characteristics of varieties, even in the conditions of the Moscow region, you can create a continuous conveyor of consumption of pumpkin fruits. Recommendations are given on the timing of dosage and use of fruits of different varieties of pumpkin selection Federal Scientific Vegetable Center.

Keywords: pumpkin, variety, hybrid, dosage, storage, biochemical composition, technological qualities.

For citation: Khimich G.A., Korotseva I.B. CONVEYOR OF VARIETIES OF PUMPKIN OF FEDERAL RESEARCH VEGETABLE CENTER (VNIISSOK) SELECTION. Vegetable crops of Russia. 2018;(1):63-65. (In Russ.)
Тыкву выращивают ради получения спелых

плодов, пригодных для хранения. Их употребляют, в основном, в зимний период, когда ассортимент овощей ограничен, в свежем, вареном, жареном, тушеном и других видах.

Тыква - продукт с высокой пищевой и биологической ценностью. Основную массу питательных веществ плодов составляют углеводы. Зрелые плоды содержат от 1,5 до 13\% сахаров, от 1,5 до 20\% крахмала, провитамин А (каротин), витамины C, $\mathrm{B}_{1}, \mathrm{~B}_{2}$, E, соли калия, кальция, фосфорной кислоты, меди, цинка и др. [1]. Тыква главный источник каротина в растительном мире. «Каротинные» сорта тыквы дают от 4,8 до 18,0 кг/га каротина. Поэтому тыква является ценным сырьём для витаминной промышленности [7].

По многолетним данным биохимической лаборатории Грибовской овощной селекционной опьтной станции и ВНИИССОК, содержание витамина С в плодах тыквы, в зависимости от сорта колеблется от 10 до 50 мг на 100 г сырой массы.

Масло, получаемое из семян тыквы, характеризуется высоким содержанием линолевой, масляной, пальмитиновой, стеариновой жирных кислот, обеспечивающих хорошую стабиль- ность масла; токоферолов, являющихся основной частью липофильных антиоксидантов $[1,8]$.

Начиная с 1920 года по настоящее время селекционерами Грибовской овощной селекционной станции и Всероссийского научноисследовательского института селекции и семеноводства овощных культур создан цельй ряд сортов, а в последнее время и гибридов, тыквы столовой с различными по форме, размеру и окраске плодами. Эти сорта отличаются не только скороспелостью и холодостойкостью, но и высокой урожайностью, устойчивостью к болезням, повышенным содержанием в плодах сухого вещества, сахаров и рядом других качеств, отвечающих самым высоким требованиям потребителя.

Большое внимание всегда уделялось вкусовым показателям плодов, запаху, толщине и консистенции мякоти, которые могут быть специфичными для каждого сорта.

В первую очередь, учёные ВНИИССОК создавали и создают сорта для Нечерноземной зоны и более северных областей России, обладающие высокой холодостойкостью и скороспелостью. Однако многие сорта, такие как Грибовская зимняя, Грибовская кустовая, Ольга, Конфетка, Россиянка получили широкое

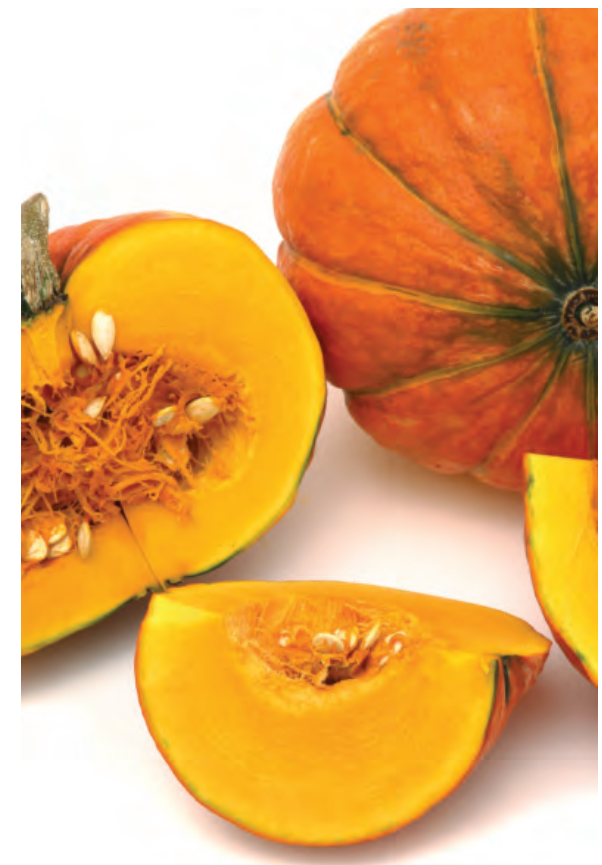

Тыква Первенец ВНИИССОК $F_{1}$. Pumpkin Pervenets VNIISSOK $F_{1}$. 


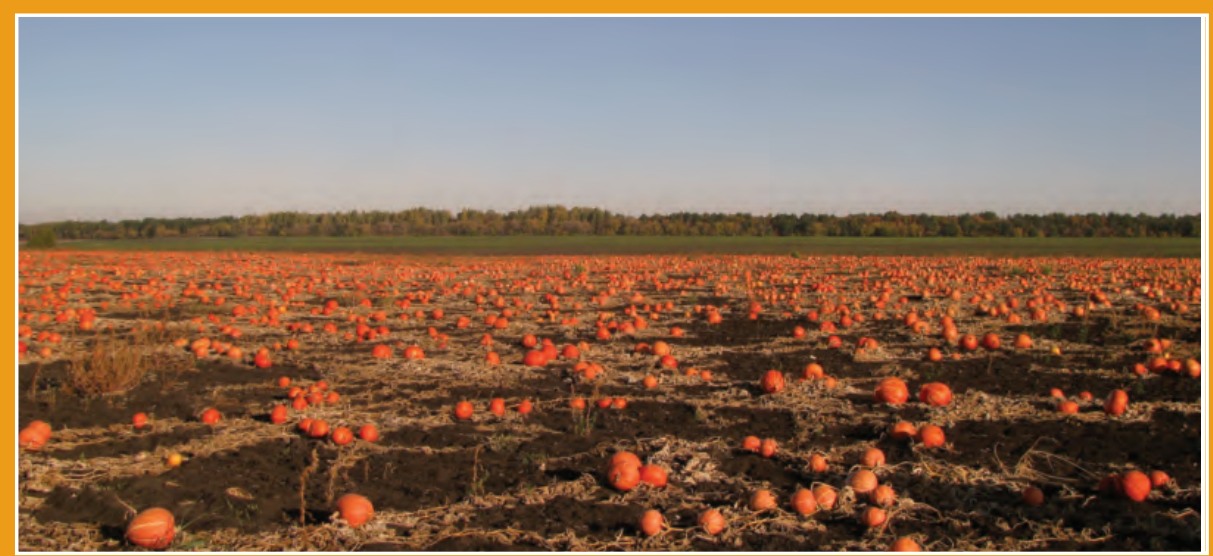

Семеноводство тыквы Россиянка

Seed production of pumpkin, cV. Rossiyanka

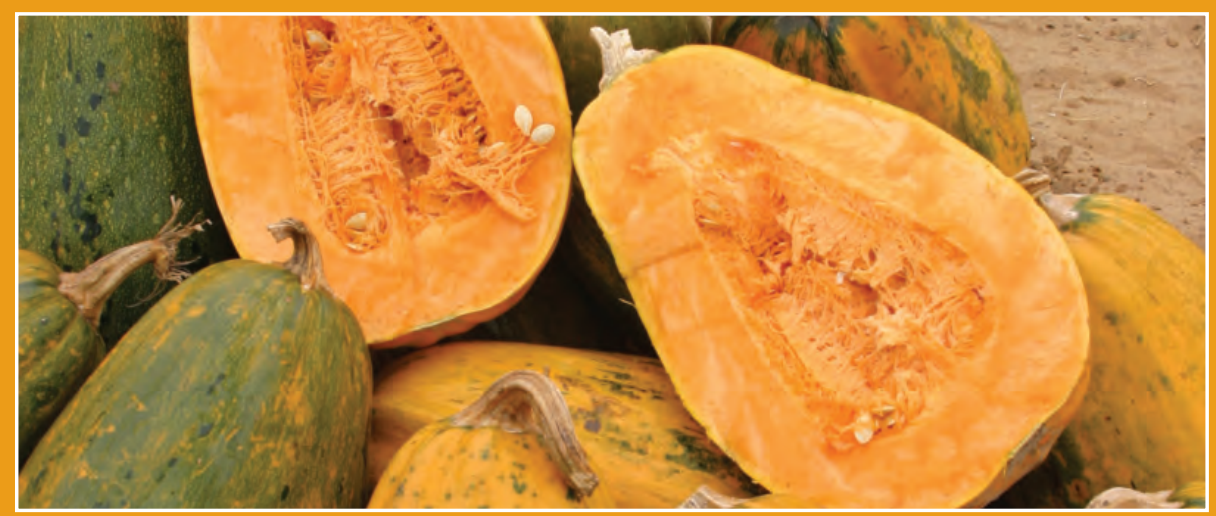

Тыква Грибовская кустовая

Pumpkin, cv. Gribovskaya kustovaya

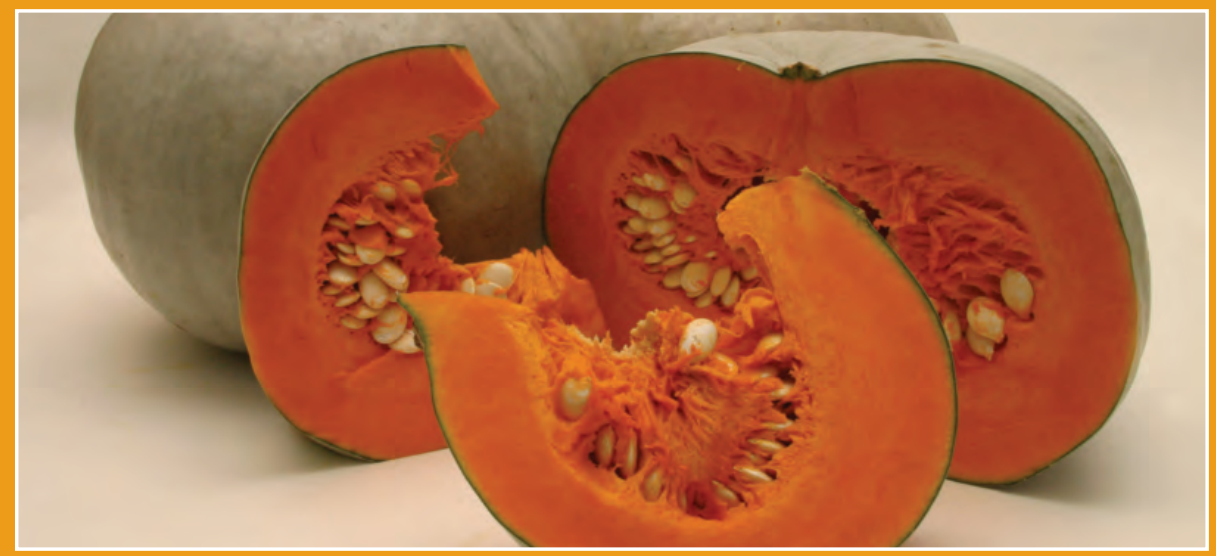

Тыква Грибовская зимняя

Pumpkin, cv. Gribovskaya zimnyaya

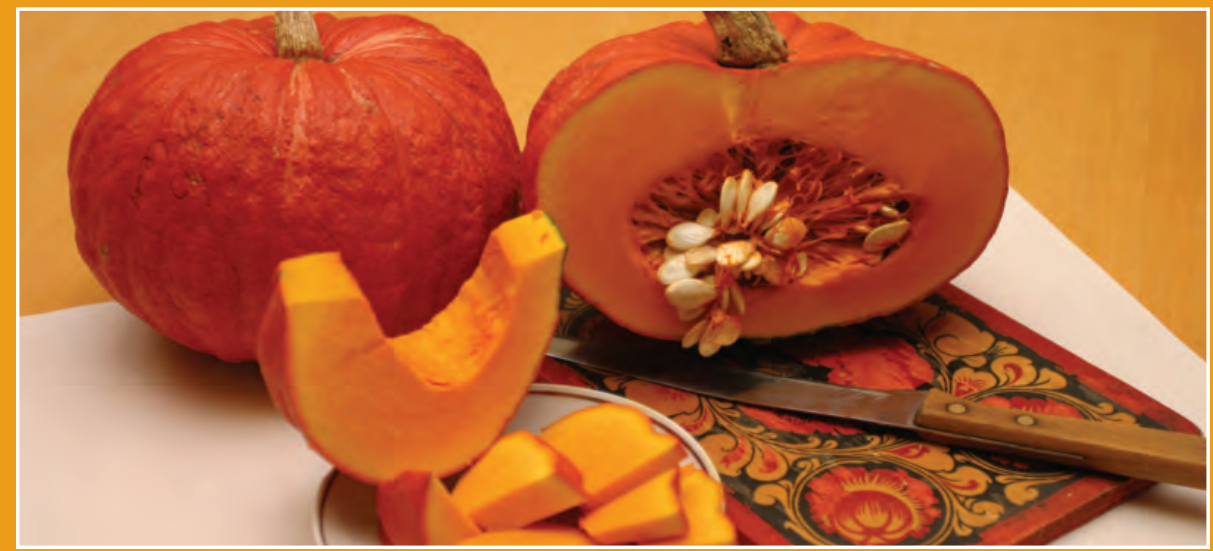

Тыква Конфетка

Pumpkin, cv. Konfetka распространение по всей Российской Федерации, в том числе и на юге России.

Используя сорта крупноплодной и твердокорой тыквы селекции ВНИИССОК, даже в условиях Московской области можно создать непрерывный конвейер потребления тыквы столовой, не вкладывая больших затрат на их выращивание, так как все эти сорта можно сеять семенами непосредственно в открытый грунт в конце мая (табл. 1).

Большинство сортов тыквы нуждается в дозаривании плодов для улучшения их вкусовых качеств. В период хранения в плодах протекает послеуборочное дозревание и другие биохимические процессы. Углеводы, которые составляют основную массу питательных веществ, при хранении подвергаются более значительным изменениям, чем многие другие составные части растительной ткани. Содержание крахмала постепенно снижается, порой на 30-40\%, а моносахаров - повышается (в среднем на 1-5\%) $[3,5,6,8,9]$. Соответственно, вкусовые качества плодов улучшаются. Однако при длительном хранении в нерегулируемых условиях, обычно более пяти-шести месяцев, ухудшаются и качественные, и вкусовые показатели [4]. Скорость этих превращений определяется энергией жизненных процессов и индивидуальна для каждого сорта. Скороспелые сорта нуждаются в более коротком периоде дозаривания по сравнению с позднеспелыми. Однако, как правило, у скороспелых сортов быстрее ухудшается качество плодов при хранении.

Ультраскороспелый сорт крупноплодной тыквы Улыбка не требует дозаривания, его плоды можно употреблять в пищу сразу после уборки. Плоды готовы к употреблению уже через 85 суток после всходов. В условиях Нечернозёмной зоны это обычно начало сентября.

Со второй декады сентября готовы к употреблению плоды крупноплодной тыквы сорта Ольга. Так же, как и Улыбка, этот сорт отличается не только скороспелостью, но и мелкими, порционными (0,7- 1,5 кг) плодами высоких вкусовых качеств.

Среднеспелый сорт Россиянка - один из самых урожайных (до 80 т/га в Нечернозёмной зоне), рекомендуется употреблять с начала октября до второй декады января. В Нечернозёмной зоне этому сорту требуется дветри недели для дозаривания плодов. Большим плюсом этого сорта является мягкая кора, которая легко очищается ножом. Мякоть плодов толстая, сухая, тёмно-оранжевого цвета, рассыпчатая, сладкая с приятным дынным ароматом. Сорт Россиянка пользуется большим спросом у переработчиков на хладокомбинатах, также из него изготавливают муку, используемую в хлебопекарной промышленности и для изготовления кондитерских масс.

Более длительного дозаривания требуют два гибрида - $F_{1}$ Вега и $F_{1}$ Первенец ВНИИССОК и сорт крупноплодной тыквы Конфетка. Их плоды лучше всего употреблять в пищу, начиная с ноября.

Гибриды $F_{1}$ Вега и $F_{1}$ Первенец ВНИИССОК отличаются высокой урожайностью и выравненностью плодов. F Вега выделяется среди других сортов высоким содержанием пектина. В тыквенном пюре содержание пектина доходило до $7,6 \%[2]$

Конфетка - один из самых сладких скороспелых сортов, пригодных для выращивания в Нечерноземной зоне России. Плоды этого сорта 
порционные, массой 2-3 кг, пригодны для употребления в свежем виде и переработки.

С начала ноября рекомендуется употреблять сорт тыквы твердокорой Грибовская кустовая, который отличается высокой товарностью плодов, не имеет специфичческого тыквенного запаха. С декабря - три позднеспелых сорта тыквы крупноплодной: Премьера, Грибовская зимняя и Москвичка. Эти сорта и гибрид $F_{1}$ Вега благодаря высоким технологическим качествам плодов, в том числе повышенному содержанию сухого вещества и сахаров, получили высокую оценку ВНИИ консервной промышленности, как исходное сырьё для изготовления детского пюре без добавления консервантов и сахара.

Грибовская зимняя является одним из наиболее популярных сортов тыкВы крупноплодной на юге России, так как его плоды широко используют в Консервной промышленности для изготовления Соков, пюре и икры.

Плоды нового сорта тыквы крупноплодной Москвичка пригодны для длительного хранения, практически до нового урожая, и предназначены для всех видов домашней и промышленной переработки: для заморозки, консервирования (детское пюре), а также использования в свежем виде - в салатах и т.д.

Изготовление пюре из плодов $F_{1}$ Вега и Москвичка обеспечивает возможность повышения в продукте концентрации сахаров в 1,8-2,0 раза, каротиноидов - в 1,3-6,3 раза, пектина - в 2-76 раз, а также улучшение вкусовых качеств и консистенции продукта по сравнению с большинством пюре, поступающего в розничную продажу [2].

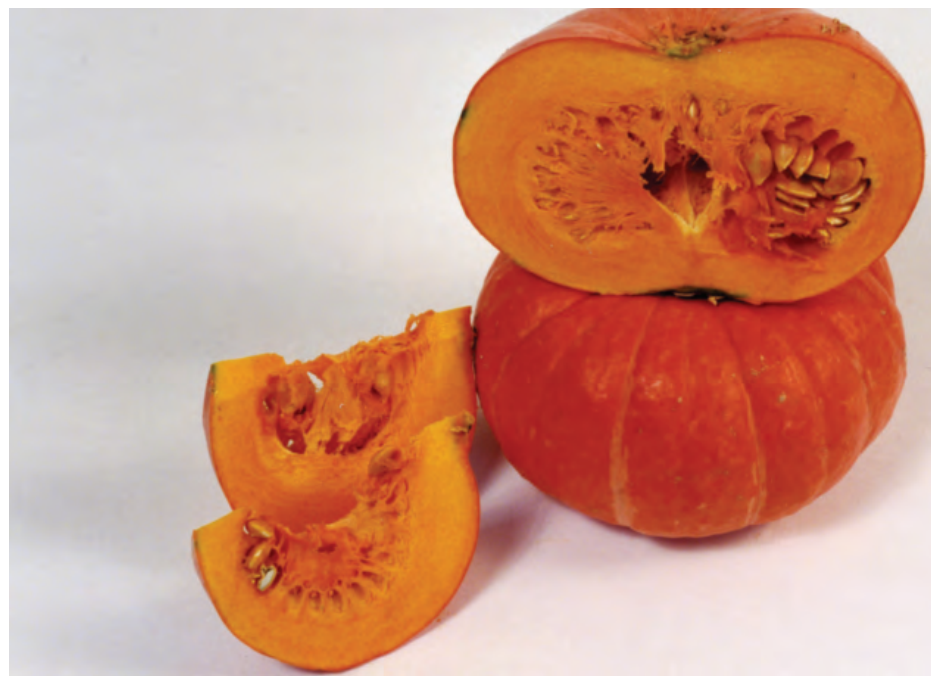

Тыква Улыбка

Pumpkin, cv. Ulibka

Продолжительность хранения плодов тыквы зависит не только от условий выращивания и хранения, но и от строения коры, сохранности плодоножки и коры, биохимического состава и плотности мякоти и ещё ряда факторов.

Большинство ранне- и среднеспелых сортов и гибридов крупноплодной тыквы, таких как Улыбка, Конфетка, Россиянка, $F_{1}$ Вега, при хранении в нерегулируемых условиях, рекомендуется употребить в течение трёх-четырёх месяцев. Исключение составляет сорт Ольга, который несмотря на скороспелость хорошо хранится до шести месяцев. Второе исключение - гиб- рид F1 Первенец ВНИИССОК, плоды которого следует употребить в течение двух месяцев.

Позднеспелые сорта, такие как Грибовская зимняя, Премьера и Москвичка после дозаривания можно хранить без потери их вкусовых и технологических качеств пять и более месяцев.

Сорт твердокорой тыквы Грибовская кустовая лучше всего употребить в течение двух с небольших месяцев.

Как видим, использование сортов с разным сроком созревания и продолжительностью хранения даёт возможность продлить потребление плодов тыквы практически до нового урожая.

Таблица. Конвейер употребления в пищу плодов столовой тыквы в условиях Московской области

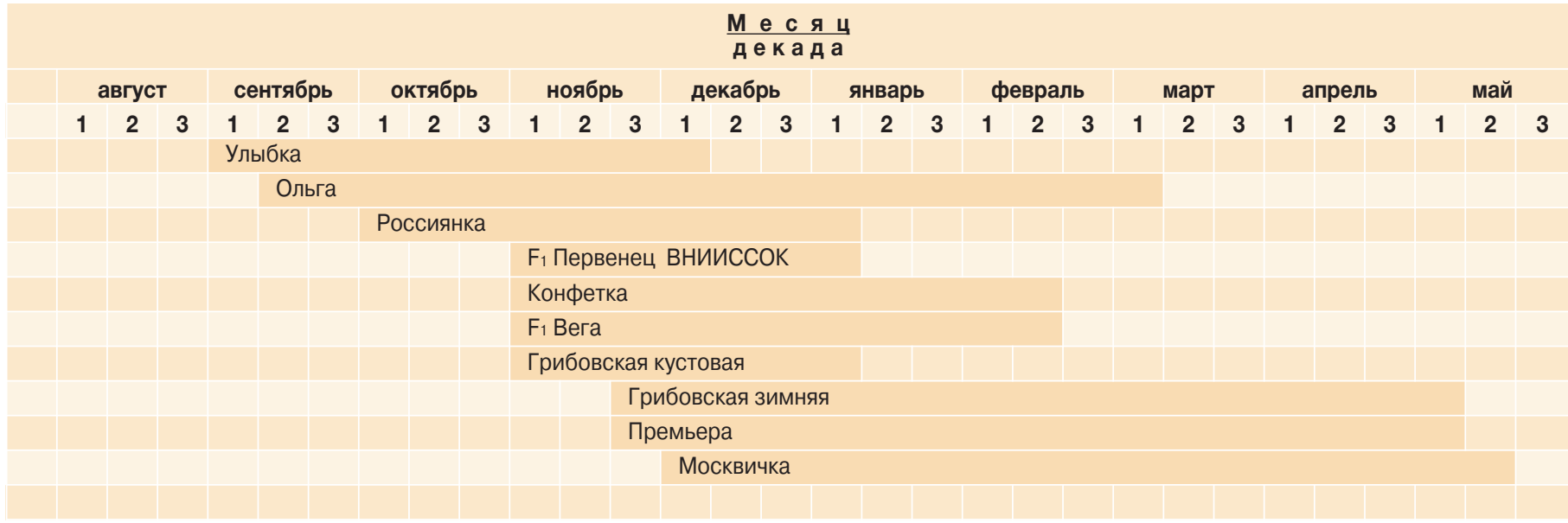

\section{- Литература}

1. Арасимович В.В. Биохимия тыквы. /Биохимия культурных растений. /Под общ. Ред. П.И. Иванова /ред. 1-14 тома Арасимович В.В.- М.- Л.: Сельхозгиз, 1938. - Т.4 С.329-349.

2. Голубкина Н.А., Терешонок В.И., Коротцева И.Б. Новые сорта тыквы в производстве тыквенного пюре. -М., 2014.-Вып.1.-С.210-213.

3. Гранкина Н.А., Борисенко В.В., Николаенко С.Н. Изменение химического состава плодов тыквы в процессе хранения. //Молодой учёный, 2015.-№22.-С.103-106.

4. Карапетян А.С. Изменение биохимического состава плодов тыквы в зависимости от сроков хранения. //Овощи России, 2015.-№1 (26).-С.48-51.

5. Николаенко С.Н. Биохимические особенности каротинсодержащего растительного сырья и его биологическая оценка: дис....канд. техн. наук /Николаенко Самвел Николаевич.- Краснодар, 2005

6. Николаенко С.Н. Волкова С.А., Николаенко В.И. Каротиноидный состав плодов тыквы //Молодой учёный, 2015.-№1(81).-С.166-168.

7. Юрина О.В., Пивоваров В.Ф., Балашова Н.Н. Селекция и семеноводство тыквенных культур в России.- М., 1998.- 423 с.

8. Хусид С.Б. Физиолого-биохимические аспекты подбора сортов тыквы для использования в кормопроизводстве: Автореферат дис. ...к. с.-х. наук./ Хусид Светлана Борисовна.- Краснодар, 2013.- 23 с

9. Хусид С.Б., Петенко А.И. Изменение химического состава плодов тыквы в процессе хранения // Сборник научн. трудов по материалам международной научно-практической конференции.- Одесса, 2012.-С.47-48.
- References

1. Arasimovich V.V. Biochemistry of pumpkin. Biochemistry of cultivated plants. Under the Society. Ed. P.I. Ivanova / Ed. 1-14 of the volume of Arasimovich V.V. - M.-L . Sel'khozgiz, 1938. - T.4.- P.329-349.

2. Golubkina NA, Tereshonok VI, Korotseva IB New varieties of pumpkin in the production of pumpkin puree. - M., 2014. - Issue 1. -P.210-213.

3. Grankina NA, Borisenko VV, Nikolaenko SN Change in the chemical composition of pumpkin fruits during storage. // The young scientist, 2015. - №22. - P.103-106.

4. Karapetyan A.S. Change in the biochemical composition of pumpkin fruits depending on the shelf life. // Vegetable crops of Russia, 2015. - №1 (26). - P.48-51.

5. Nikolayenko S.N. Biochemical features of carotene-containing plant raw materials and its biological assessment: dis ... .kand. tech. Sciences / Nikolaenko S.N. - Krasnodar, 2005.

6. Nikolayenko S.N. Volkova S.A., Nikolayenko V.I. The carotenoid composition of the pumpkin fruits // Young Scientist, 2015. - No.1 (81) - - P.166-168.

7. Yurina O.V., Pivovarov V.F., Balashova N.N. Breeding and seed-growing of pumpkin cultures in Russia . - M., 1998. - 423 p.

8. Khusid S.B. Physiological and biochemical aspects of the breeding of pumpkin varieties for use in fodder production: Abstract of the dis. ...to. agr. sciences / Husid S.B.Krasnodar, 2013. - 23 p.

9. Khusid S.B., Petenko A.I. Changes in the chemical composition of pumpkin fruits in the course of storage // Proc. works on the materials of the international scientific and practical conference. - Odessa, 2012 - P.47-48. 